\title{
Processo de supervisão em jardim de infância. Um olhar narrativo em prol do desenvolvimento profissional
}

\author{
Susana Meirinhoi \\ Escola Superior de Educação de Torres Novas, Portugal \\ Cecília Galvãoii \\ Universidade de Lisboa, Portugal
}

\begin{abstract}
Resumo
Este artigo baseia-se num processo de supervisão que visou escutar duas educadoras de infância que contaram as suas experiências, de forma a darem a conhecer as suas práticas educativas. Este processo de supervisão colaborativo reflexivo foi evidenciado nas histórias das educadoras como promotor de desenvolvimento profissional e de melhoria de práticas educativas, sendo a reflexão o elemento central para esse desenvolvimento, permitindo a atribuição de sentido da ação pedagógica. O estudo é de natureza qualitativa e interpretativa e foi a narrativa o método de escuta e reflexão, sendo utilizado, para a análise das narrativas, o modelo avaliativo de Labov $(1972,1982)$. O estudo sugere que o processo de reflexão integrado na supervisão permitiu uma melhoria de práticas educativas e, consequentemente, do desenvolvimento profissional. Com o contar histórias, as educadoras relembram, analisam e incorporam a reflexão das suas experiências educativas nas suas práticas.
\end{abstract}

Palavras-chave

Supervisão; Educação de infância; Desenvolvimento profissional; Narrativas

\section{Introdução}

O jardim de infância nestes últimos anos tem sido reconhecido como um espaço de aprendizagens múltiplas, onde se torna fundamental a 
qualidade das práticas educativas, preservando a "identidade própria" da educação de infância (Parecer n ${ }^{\circ}$ 3/2009, de 26 de junho).

Este artigo pretende situar-se em dois níveis que se intersetam para a leitura das experiências educativas acontecidas em jardim de infância. Um primeiro nível refere-se ao processo de supervisão de cariz colaborativo e reflexivo, que envolve educadoras, crianças e supervisor. E um segundo nível ao das práticas educativas das educadoras de infância como promotoras de aprendizagens significativas para as crianças. É o cruzamento destes dois níveis que contribuirá para uma educação de qualidade, que impulsionará o sucesso de crianças pequenas no decorrer da sua vida escolar (UNESCO, 2010).

Woodhead (1996) diz-nos que a qualidade educativa na educação de infância está fortemente influenciada por vários fatores, dos quais se destacam as práticas dos educadores. Essas práticas deverão refletir o que se sabe sobre o desenvolvimento das crianças (a investigação) e integrar realidades da vida das crianças (serem contextualizadas). Moss, Dahlberg, e Pence (2000) fazem emergir um novo conceito, o de make meaning atribuição de sentido -, que associamos às duas ideias anteriores. Para estes autores, construir e aprofundar a compreensão do trabalho pedagógico é o que garante uma proposta para criar sentido (make meaning) para a realidade existente. Este conceito está intimamente relacionado com a supervisão e implica um processo de escuta das educadoras, através do qual relatam acontecimentos e as suas inquietações relacionadas com as práticas que desenvolvem. É neste contexto que este artigo pretende dar voz às educadoras de infância de modo a aceder às suas experiências educativas, bem como aos significados que Ihes atribuem (Clandinin \& Connnelly, 2000). E é neste processo de escuta que se revelam aprendizagens, num contar histórias com sentidos pessoais, mas também sociais e profissionais.

\section{A supervisão e o desenvolvimento profissional}

A supervisão caracteriza-se, neste artigo, como "atuação de monitorização sistemática da prática pedagógica" em que os procedimentos centrais que a suportam são a reflexão e a experimentação (Vieira, 1993, p. 28). Neste âmbito, "a aprendizagem que se gera na prática é um elemento 
formativo" e a supervisão, consequentemente, permite desenvolvimento, aprendizagem e melhoramento na educação (Alarcão, 1996, p. 17). O conceito de supervisão, aqui apresentado, é entendido além da formação inicial, sendo ampliado numa perspetiva de formação, aprendizagem e aperfeiçoamento ao longo da vida, numa amplitude de promoção da qualidade educativa.

Glickman (1985) considera três estilos de supervisão: não-diretivo, de colaboração e diretivo. O supervisor que adota um estilo não-diretivo evidencia interesse e capacidade de atender ao professor, escutando-o e valorizando as suas ideias e saberes, encorajando-o nas duas decisões. 0 supervisor colaborativo faz sínteses das sugestões e dos problemas apresentados, ajuda a resolvê-los. Esta dimensão colaborativa assume-se como condição de qualidade, facilitadora de melhores práticas, um verdadeiro "instrumento ao serviço do desenvolvimento" (Alarcão \& Canha, 2013). Estes dois estilos permitem que no decorrer do processo se faça reflexão sobre a atuação do educador, possibilitando a identificação de teorias e/ou crenças que Ihe estão implícitas. Assim, faculta o autoconhecimento e uma progressiva construção do seu estilo pessoal de atuação (Oliveira, 1992). Neste âmbito, os educadores tomam decisões pedagógicas fundamentadas, o que permite uma maior adequação ao desenvolvimento das crianças. $O$ supervisor de tipo diretivo, pelo contrário, concentra as suas preocupações em dar orientações, em estabelecer critérios e condicionar as atitudes do professor. De facto, entre outras metas, a supervisão promove o desenvolvimento pessoal e profissional dos professores (Reiman \& ThiesSprinthall, 1998; Alarcão, 1996). Assume-se que os professores têm um papel como agentes de mudança, em que o desenvolvimento profissional será um indicador da qualidade que se procura no campo da educação (UNESCO, 1998).

Nesta configuração, o processo de supervisão enquadra a aprendizagem profissional de um modo contínuo que envolve a pessoa e os seus saberes, assumindo-se como uma "prática acompanhada, interactiva, colaborativa e reflexiva" (Sá-Chaves, 2000, p. 75). Esta é uma perspetiva de supervisão que assenta em pressupostos da teoria construtivista e desenvolvimentista, que reconhece que os professores têm potencialidades para melhorar o seu estilo de ensino. Assim, a supervisão perspetiva "a 
formação e o desenvolvimento profissional dos agentes de educação e a sua influência no desenvolvimento e na aprendizagem dos alunos" (Vasconcelos, 2009, p. 94).

A supervisão assume um papel de escuta das experiências educativas dos educadores, onde evidenciam os seus saberes, questões e reflexões das práticas contextualizadas (Sá-Chaves, 2002). Esta é uma perspetiva de supervisão em que emerge o desenvolvimento profissional numa constante reflexão sobre o já experimentado para a (re)construção de novas experimentações. A supervisão surge como alicerce da construção e desenvolvimento do conhecimento profissional (Alarcão \& Roldão, 2008), permitindo aparelhar os "andaimes, as estruturas de apoio e revê-las constantemente" (Vasconcelos, 2009, p. 97), de um modo dinâmico onde se valoriza as experiências aliadas à reflexão, em todo o processo desenvolvimental dos professores (Fullan, 1982). Este processo traduz-se num "trabalho de reflexividade crítica sobre as práticas e de (re)construção permanente de uma identidade pessoal" (Nóvoa, 1992, p. 25).

Apresentando um paradigma de prática reflexiva, Zeichner (1993) caracteriza o desenvolvimento profissional dos professores como uma atitude de questionamento sistemático face às conceções, práticas e contextos de ensino-aprendizagem. Assim, é uma abordagem reflexiva que apresenta uma visão de melhoria e desenvolvimento, através da aprendizagem, num panorama em que os professores constroem e reconstroem o seu conhecimento no campo da ação, acontecendo num ambiente situado, de diálogo com outros e numa constante mobilização de saberes (Alarcão, 2002; Sá-Chaves, 2011).

Schön (1983, cit. por Alarcão, 1996) revaloriza o conhecimento contextualizado que floresce da prática inteligente e refletida, considerando estes dois elementos, em paralelo, o que desafia os profissionais. A reflexão é considerada uma forma de compreender e reconstruir a ação. Entendendo o processo de supervisão como contributo para momentos de reflexão, Schön (1987, cit. em Alarcão, 1996) indica como estratégia fulcral de reflexão a verbalização do pensamento como expressão dos processos de reflexão na ação e diálogo com a situação. Assim, permite aceder a significados e negociar a construção de novos sentidos. 
É, certamente, num processo de reflexão conjunta, com outros, que construímos novos sentidos para as práticas e se produz desenvolvimento e aprendizagem, esta suportada numa forte articulação teoria/prática, bem como entre a prática e a reflexão sobre a prática, como defende Perrenoud (1993). Brookfield (1995) também concorda que um professor reflexivo crítico chegou à particularidade do processo de reflexão. É neste processo crítico que o professor se questiona e analisa as suas práticas, bem como o impacto em termos de aprendizagens nos alunos. Este nível só é concretizável porque consegue estar disponível para o diálogo com outros, partilhando diferentes opiniões e visões de realidade experimentada, o que consequentemente valida novos significados e até novas formas de atuação futuras.

\section{A narrativa no processo de escuta}

O Ser humano é um ser social e está rodeado de experiências de vida diversas, situadas num tempo e espaço. Bruner (1972) considera que é através da linguagem que essas experiências de vida são expressas. É com esse instrumento que os outros acedem ao pensamento de alguém, permitindo desenvolvimento e construção de conhecimento. Assim, a narrativa torna-se "a melhor forma de representação e compreensão da experiência" (Clandinin \& Connnelly, 2000, p. 18).

É com este sentido que a importância da narrativa em contexto de educação se revela. A narrativa surge como um modo de refletir, relatar e representar a experiência, permitindo a produção de sentido para a mesma (Carter, 1993). Considerando a perspetiva de Riessman (1993), a experiência vivida assume cinco níveis de representação: dar sentido, contar, transcrever, analisar e ler. No entanto, todo este processo inclui um sexto nível, o da interpretação (Galvão, 2005), evidenciando novas formas de compreensão, pelo próprio e pelos outros que acedem ao relato. Entramos, deste modo, cada vez mais em profundidade, nos múltiplos sentidos que a experiência pode ter.

$\mathrm{Na}$ educação, a narrativa assume-se como uma forma de conhecer a realidade educativa, mas também como impulsionadora do desenvolvimento pessoal e profissional dos professores (Reis, 2008). Assim, poder-se-á compreender melhor as diferentes formas de pensar dos professores, bem 
como os processos de ensino-aprendizagem que desenvolvem e o modo como os percebem. É nesta perspetiva que o professor tem oportunidade de orientar, "com lucidez, as próprias aprendizagens e o seu processo de formação" (Josso, 2004, p. 41), podendo, assim, alicerçar melhorias na sua ação educativa.

Galvão (2005) apresenta diferentes potencialidades da narrativa, encontrando-se estas em três processos essenciais na educação: a investigação, a reflexão pedagógica e a formação. Em todos eles a narrativa tem benefícios ao permitir criar novas estratégias e melhorar práticas de atuação. No entanto, Clandinin e Connelly (2000) alertam-nos para o facto de em educação existirem muitas formas de narrativas. Situando-nos no conceito, Stephens (1992) diz que a narrativa se constitui pela história, mas também pelo discurso e significação atribuída por outros. Connelly e Clandinin (1990) diferenciam a narrativa da história, considerando a história como os acontecimentos experienciados e a narrativa o método que estuda, descreve e compreende essas experiências (Galvão, 2005). De facto, como Bruner (1997) nos diz que a narrativa é um tipo de pensamento que expressa um saber, talvez com as várias interpretações possíveis se possa alargar para vários saberes. A utilização da narrativa permite comunicar com outros, bem como descodificar experiências vividas pelos professores, num contexto próprio, particular, mas próximo e imerso na sua realidade educativa. Assim, a narrativa apresenta-se de forma a reconstituir o significado contido nas ações dos professores, valorizando o seu saber prático (Galvão, 2005).

Labov $(1972,1982)$ propõe um modelo sociolinguístico de análise das histórias de professores, considerando história uma narrativa muito particular de que se destaca, de uma forma simplista, um princípio, um meio e um fim. De acordo com o autor, as histórias apresentam-se com uma estrutura constituída por seis componentes: resumo (o sumário da narrativa); orientação (indicações laterais à ação, como personagens, tempo e espaço); complicação da ação (os acontecimentos centrais que implicam uma trama); resolução (o modo como foi resolvida a situação, ou a resposta do próprio sobre determinado acontecimento); avaliação (o sentido dado pelo próprio ao modo como resolveu a situação); e coda (palavra latina que significa fecho e que, neste modelo, implica virar o sentido para o presente, o continuar da história). Este método de análise, também designado de avaliativo, permite 
aceder às experiências primárias de quem narra (Riessman,1993) e também à avaliação que faz desses relatos descritivos. A reflexão sobre um acontecimento ajuda a evidenciar o sentido das experiências, e este é, certamente, um processo de criação de histórias. Essas histórias só existem porque alguém as conta a partir de uma experiência primária a que dá sentido. A sua escuta e acolhimento permitem reflexões e troca de experiências que revelam aprendizagens e promovem o desenvolvimento (Elbaz-Luwisch, 2007), elevando o papel da narrativa como elemento que valoriza os saberes dos professores, atendendo a todos os detalhes (Elbaz-Luwisch, 2005).

Considerando o que foi dito, de facto as narrativas em educação permitem aos professores conhecer a sua realidade educativa, mas também aprender, desenvolvendo-se e construindo aprendizagens. Para Roldão (2004), a construção de conhecimento que acontece ao longo da vida necessita de duas operações: analisar e imaginar. A primeira, analisar, implica a capacidade de colocar questões pertinentes para conhecer o real. A segunda, imaginar, suporta a competência explicativa, o pensar e interpretar o real. Neste contexto, a narrativa surge, em educação de infância, com todas estas facetas que têm vindo a ser enunciadas. Torna-se uma forma respeitadora de sentir, pensar e fazer em educação de infância, e que permite valorizar os saberes dos educadores, possibilitando aceder ao sentido da ação pedagógica desenvolvida por cada um.

\section{Metodologia}

Este estudo é uma componente de uma investigação mais abrangente que deu origem a uma dissertação de mestrado. $O$ objetivo central era descrever e compreender práticas educativas no âmbito de aprendizagens em ciências, num contexto de supervisão em jardim de infância. Em todo este trabalho, privilegiou-se a escuta dos significados atribuídos pelas crianças e educadoras às atividades no domínio das ciências. Todo o processo supervisivo contemplou o planeamento, ação e reflexão desenvolvida pelas educadoras de infância relativamente à evidência de aprendizagens em ciências, bem como às respostas dadas pelas crianças durante as atividades propostas. Apesar de este trabalho ter sido desenvolvido em torno do domínio das ciências, neste artigo apresenta-se apenas a parte que realça os aspetos supervisivos de todo o processo. 
No estudo optou-se por uma metodologia de tradição interpretativa (Cohen, Manion, \& Morrison, 2000) e de carácter qualitativo (Creswell, 2003). Pretendeu-se que os sujeitos participantes no estudo atribuíssem significado às experiências educativas em jardim de infância e relatassem as suas representações acerca do processo de supervisão proposto. Sendo o conceito de supervisão muito alargado, optou-se por uma modalidade de supervisão proposta por Glatthorn (Vasconcelos, 2009, p. 90) e designada de desenvolvimento profissional cooperativo. Neste contexto, criou-se um pequeno grupo de trabalho constituído por duas educadoras de infância e uma supervisora externa, professora de uma Escola Superior de Educação. Neste processo colegial, em conjunto, fizeram observação das sessões planeadas, discussão de problemas profissionais, colaboração na preparação de materiais e reflexões conjuntas. A professora supervisora já tinha trabalhado com as educadoras em processo de cooperação, no âmbito da Iniciação à Prática Profissional enquanto estudantes da Licenciatura em Educação Básica.

Assim, considerando, neste estudo, a importância da supervisão no processo de desenvolvimento profissional e, consequentemente, na melhoria de práticas educativas, definiu-se a seguinte questão de investigação (integrada numa problemática mais vasta, como já se referiu): Qual o contributo do processo de supervisão para o desenvolvimento profissional das educadoras envolvidas?

A investigação aconteceu em duas salas de jardim de infância da faixa etária dos 4 e 5 anos. Participaram, no estudo, duas educadoras de infância de um jardim de infância, de meio urbano, da rede pública do Ministério da Educação e Ciência, pertencente ao distrito de Santarém. Os dados foram recolhidos entre janeiro e maio de 2012 e a recolha foi efetuada durante $o$ processo de supervisão das duas educadoras participantes. Foram realizadas duas entrevistas formais a cada educadora, uma no início do estudo e outra no fim do processo de supervisão. Com as entrevistas pretendemos aceder ao sentido que as educadoras dão às suas práticas e aos acontecimentos, bem como às reflexões surgidas num contexto de supervisão colaborativo. As entrevistas foram alvo de análise narrativa, sendo que, neste estudo, a narrativa se assume como privilegiada e principal método de recolha, análise, reflexão e interpretação da informação recolhida, assumindo as suas 
potencialidades investigativas (Galvão, 2005). Pretende-se atribuir significado às experiências vividas, relatadas e escutadas das educadoras no que respeita à supervisão. É nesta linha que, neste estudo, se reconhece a narrativa como um método que privilegia o "conhecimento prático dos professores" (Connelly \& Clandinin, 1990), em que se incluem até as crenças, emoções e valores pessoais.

Das narrativas das educadoras, foram selecionadas histórias e utilizado um modelo sociolinguístico de análise, sendo este a estrutura da narrativa, proposto pelo modelo avaliativo de Labov $(1972,1982)$. Essas histórias têm padrões característicos que incluem seis elementos: resumo, orientação, complicação da ação, resolução, avaliação e coda. Assim, a análise sociolinguística proposta por Labov $(1972,1982)$ permite organizar a informação recolhida, colocar em evidência os resultados da investigação e apresentar uma visão avaliativa das educadoras participantes do estudo sobre as ocorrências.

\section{Apresentação e análise dos dados}

\subsection{A supervisão no processo de desenvolvimento profissional}

\subsubsection{Antes do processo de supervisão}

As práticas de supervisão são variadas e nem sempre existe consenso em relação ao próprio conceito. Por este motivo, antes de iniciar o processo de supervisão as educadoras assumiam uma ideia de supervisão que se traduz nas histórias seguintes:

História 1

Eu procuro, e acho que há sempre muitos benefícios. Porque, lá está, não vamos ser só nós, digamos. Vamos ser quem vai realizar juntamente com as crianças, (resumo)

e aí vamos refletir, vamos pesquisar, não é, vamos arranjar, vamos elaborar uma planificação e depois que na prática, não é, vais de encontro àquilo que queremos provocar na criança, não é? Que a criança adquira essas competências e esses conhecimentos (avaliação)

Vai-me enriquecer porque eu vou trabalhar, (avaliação) 
não vão ser só as minhas ideias, (complicação da ação)

vão ser em conjunto com outras pessoas, não é?, que vai tornar as atividades mais ricas. (resolução)

Expectativas. É assim, são boas, são sempre muito positivas, não é? Porque nós aprendemos, inovamos e tornamos a nossa rotina diária mais diversificada. Mas, também, por outro lado, é sempre um risco porque nos vai fazer quebrar essa rotina, vamos ter que pesquisar. (avaliação)

Eu por acaso não faço sempre a mesma coisa, mas mesmo assim, acho que é sempre motivador. (complicação da ação)

Por um lado temos as vantagens, mas por outro lado vai faltar-nos aquele apoio, aquela segurança, porque vamos estar a fazer coisas, se calhar, um bocadinho mais, como é que eu vou dizer, pronto, é isso, o sentir segurança, vai ficar um bocadito mais fragilizada. É. (avaliação)

É realmente a planificação conjunta. Ah. E aí já engloba, não é?, os materiais, as atividades, e depois também o partilhar, fora da escola, a outras colegas, a outros docentes, à comunidade, os resultados deste trabalho e ouvir os feedbacks de quem está de fora. (resolução)

O contributo é assim. A supervisão ah, ah se não for para outra coisa, vai-nos fazer refletir, não é? Vai-nos fazer refletir e é isso que acho que faz falta, cada vez mais, a gente refletir sobre o trabalho que nós estamos a fazer e, lá está, crescer, atualizar-nos, inovarmos. (avaliação)

E pronto. É crescer. (coda)

(educadora P1)

\section{História 2}

O desenvolver profissionalmente é assim, nós temos que estar nesta função como alguém aberto a aprendizagens. Eu sinto que, como educadora, tenho aspetos bons e que sei lidar, (resumo)

e tenho aspetos mais frágeis, não é? (complicação da ação)

Mas a observação, a cooperação, para mim é um elemento de limar certas arestas. Eu vejo como algo positivo, não é?, e não vejo como um elemento agressor, um elemento invasivo, um elemento que me vá perturbar. Posso ficar com a expectativa de como as crianças vão reagir, como é que 
vão estar com mais um elemento na sala, como é que vai ser o seu comportamento, a sua forma de estar, a sua forma de adesão. É sempre imprevisível, e ficamos sempre na expectativa. Vai correr bem, não vai correr bem. (avaliação)

Acho que é alertar, sugerir, também orientar, porque eu gosto muito que me digam se estou bem, se estou mal. Como é que eu posso dizer?... Eu faço as coisas de uma forma em que quero promover alguma coisa, é óbvio, mas também pode haver falhas noutro setor,

e eu gosto de ouvir, porque assim nós ao mesmo tempo trabalhamos connosco próprios. Eu tive sempre educadores de apoio na sala, (orientação)

tive uma educadora voluntária, eu sempre gostei, e dizia muitas vezes: "O que é que vocês acham? Está correto? Não está correto?", porque eu não penso que sei aquilo, que sou suprassumo. Não, nada disso. Eu vejo que quem está na educação, quem está com crianças, é assim, nós temos que limar, temos que evoluir em certos aspetos. (resolução)

$E$ eu não tenho em mim... Faço o melhor que posso e promovo conhecimento nas crianças, tenho consciência que promovo conhecimento, promovo entusiasmo nas atividades, promovo a empatia, promovo a amizade, promovo a cooperação, mas também temos as fragilidades. Basta sermos pessoas, não somos perfeitos, e eu gosto muito do feedback. (avaliação)

E eu dizia assim: "O que é que vocês acham disto?", "Tás bem, P2, tás ótima!". (resolução)

E eu não ficava satisfeita, porque eu preciso de uma crítica construtiva. Mas verdadeira. E há coisas que eu gostaria de limar, (avaliação)

mas só alguém estando de fora a observar-me, não é? Pode dar-me certas orientações, certas perspetivas que eu poderei aplicar futuramente. (resolução)

Eu penso que vai ser muito positivo, a implicação só pode ser positiva, nunca pode ser negativa. Não há razão nenhuma, tem que ser positivo, porque elas também têm que perceber que há outro elemento na sala e também elas vão testar, e vão questionar, mas isso é mesmo assim. (avaliação)

E acho que para mim é uma mais-valia. (coda)

(educadora P2) 
As duas histórias ilustram uma ideia de supervisão como um processo que beneficia as educadoras na melhoria da prática pedagógica, mas também as crianças do ponto de vista da aquisição de competências e conhecimentos. Ambas as educadoras realçam a colaboração como ponto essencial para o desenvolvimento profissional. Mostram-se como "alguém aberto a aprendizagens" (P2) e entendem a supervisão colaborativa como elemento essencial para "aprendermos, inovarmos e tornarmos a nossa rotina diária mais diversificada" e "crescer" (P1). As educadoras posicionam-se numa abertura de espírito e numa base de responsabilidade e empenhamento que Zeichner (1993) considera necessárias para acontecerem práticas educativas reflexivas que promovem $O$ desenvolvimento de aprendizagens em educadores e crianças. A educadora P2, na "orientação", aponta para a importância de uma supervisão colaborativa, visto ("nós ao mesmo tempo trabalhamos connosco próprios") existir a necessidade de escutar a voz de outros, que P1 considera na "complicação da ação".

Ao longo das histórias estão implícitas as expetativas das educadoras acerca do papel do supervisor, considerando como suas funções: observar, cooperar, alertar, sugerir, orientar, criticar construtivamente de forma verdadeira, dar "certas perspetivas", planificar em conjunto, dar feedback e refletir em conjunto. É uma perspetiva em que o foco será a partilha, construção e, consequentemente, valorização do saber prático (Galvão, 2005). A par destas perspetivas, as educadoras, nos momentos de "avaliação", vão referindo aspetos positivos do processo de supervisão, mas também alguns receios e fragilidades sentidas por cada uma. Estas duas dimensões assinaladas (positivo e menos positivo) surgem, de forma intercalada, nas histórias que esclarecem os seus pontos de vista. As educadoras revelam o desejo de uma supervisão como promotora de desenvolvimento; no entanto, este desejo aparece aliado a algumas preocupações relacionadas com a atitude do supervisor.

Síntese

É numa visão de supervisão colaborativa e contribuidora para aprendizagens que as educadoras se posicionam no início do processo. Aceitam um contexto de supervisão colaborativa em que o supervisor se torna "colaborador na análise e sínteses de novas compreensões" das práticas 
desenvolvidas e que promovem a construção de aprendizagens contextualizadas (Garmston, Lipton, \& Kaiser, 2002, p. 115). No entanto, surgem algumas inseguranças, e até riscos assumidos, que vão sendo referidas na "avaliação" das histórias de ambas as educadoras.

\subsubsection{Pós-processo de supervisão}

A supervisão assumiu-se neste trabalho como uma dimensão essencial no desenvolvimento profissional das educadoras participantes. $O$ desenrolar do trabalho cooperativo estabelecido entre educadoras e supervisora permitiu a construção de uma imagem do próprio conceito de supervisão.

Todavia, antes de iniciar o processo de supervisão, as educadoras mostram, nas suas histórias ( 1 e 2), alguns receios do próprio percurso supervisivo, que, pós-processo, se diluem, conforme as histórias seguintes nos mostram:

\section{História 3}

Esta supervisão para mim foi uma novidade, não pela pessoa, mas da forma como foi posta em prática. (resumo)

Já estive em dois tipos de supervisão, e digo pessoalmente que a supervisão tem que ser nos moldes que foi dinamizada, (complicação da ação)

Porque para já incutiu-nos uma prática de pesquisa, de estar mais atenta àquilo que as crianças nos solicitam, depois o facto de nos ajudar a organizar, a estruturar as atividades de modo a que a intenção educativa fizesse sentido para o grupo e para mim enquanto educadora. $E$ depois $o$ facto de refletirmos sobre o agir, de forma construtiva, de forma a melhorar, acho que qualquer pessoa... (resolução)

e eu estou feliz por me ter proporcionado este momento, só tenho é que estar agradecida porque me tornou uma pessoa a ver as coisas de outra maneira, em termos de supervisão. Eu acho que só neste sentido é que as práticas e nós, como pessoas, podemos melhorar. É o que eu sinto, não pode ser de outra maneira, a gente não é criticar ou chamar a atenção como 
apontar o dedo, mas não, reflexão em conjunto: "Aconteceu isto. Como é que se pode fazer melhor?". E eu estou aberta sempre a isso, também é importante que as pessoas tenham esse tipo de abertura para tentarem sempre serem melhores, não só como pessoas, mas também como profissionais que somos. Eu gostei muito da forma como foram todas as etapas deste trabalho. (avaliação)

Gostei muito (avaliação/coda)

(educadora P1)

História 4

Todo o processo de supervisão eu achei muito interessante, e achei que houve um interesse tanto da minha parte como da S. [supervisora] em que a atividade se processasse de uma forma interessante para as crianças, em que a atividade promovesse conhecimento para as crianças e que ela fosse uma coisa viável e com lógica, com sentido. E houve um empenho da S. também que (resumo)

este processo se desenvolvesse de uma forma consciente, (complicação da ação)

e não de uma forma tão leve. E eu achei interessante esta cumplicidade entre a pessoa que está a observar a prática pedagógica, não no intuito de penalizar com alguma coisa que não tenha corrido tão bem, mas sim haver essa colaboração e essa cumplicidade para que as coisas resultassem de uma forma pedagogicamente mais correta. (avaliação)

Enquanto desenvolvimento profissional é uma aprendizagem para mim, porque a minha forma, até de introduzir o diálogo e a exploração do tema, as perguntas a fazer às crianças, veio-me ajudar a dizer que eu tenho de ter um tempo de espera mais amplo, não ter receio daquilo que as crianças possam dizer e da minha parte haver essa introspeção, essa reflexão, porque se tem medo que a criança não atinja aquilo que é pretendido e aprendi que não temos que ter esse medo. E que temos que ter esse tempo de espera, de saber ouvir as crianças, sem receio. (resolução)

E eu acho que para mim foi bom, e repetia, outra vez, todo o processo. (avaliação)

(educadora P2) 
Ambas as histórias evidenciam dois estilos de supervisão que pressupõem atitudes diferentes por parte do supervisor e são descritas na "avaliação" das educadoras. Um primeiro estilo de supervisão em que o papel do supervisor é o de "criticar ou chamar a atenção como apontar o dedo" (P1) e com o "intuito de penalizar com alguma coisa que não tenha corrido tão bem" (P2). As educadoras fazem referência a uma supervisão diretiva (Glickman, 1985) e dão a entender que já estiveram envolvidas nesse processo. Um segundo estilo de supervisão é aquele apontado pela educadora P1 na "'complicação da ação" e que a permitiu "ver as coisas de outra maneira, em termos de supervisão", reconstruindo o próprio conceito. A educadora P2 caracteriza-o como colaborativo, em que a base foi estabelecer uma relação de cumplicidade entre supervisor e educadora. Esta supervisão colaborativa corresponde a uma "resolução" que impulsionou algumas mudanças na ação educativa. É um processo que revela valorização dos saberes destas educadoras, bem como aprendizagem e desenvolvimento na sua ação educativa (Elbaz-Luwisch, 2005, 2007).

As histórias 3 e 4 revelam a importância da reflexão no momento de "resolução", mas também, com igual valor, no processo de "avaliação" realizado pelas educadoras. A educadora P2 considera-a, na "complicação da ação", o motor da sua aprendizagem profissional. No que respeita à prática educativa, a ação supervisora de cariz colaborativo e reflexivo (Sá-Chaves, 2000) permitiu melhorias na atividade pedagógica. As histórias seguintes complementam esta visão, já descrita nas histórias 3 e 4:

\section{História 5}

Neste momento, o facto de estar na minha sala [a supervisora] já é um elemento. A forma como fez supervisão, (resumo)

acho que nos fez crescer. (complicação da ação)

para já o planear, organizar as atividades de modo a que nada pudesse falhar, materiais, o tipo de respostas, as conclusões. Desenvolveu também competências em nós neste tipo de áreas, deixámos de recear, de evitar as coisas devido ao produto final. (resolução)

O processo de supervisão foi muito positivo. Acho que foi muito importante porque a necessidade de saber qual o conteúdo científico, a 
preocupação de tentar saber mais, pensarmos as estratégias. O facto de estar como supervisora colaborante, também como amiga, dá-nos a tal segurança, (avaliação)

ao fim de tantos anos de serviço até talvez não poderemos falar de segurança, (orientação)

mas sim tem a ver com desenvolvimento, e nós queremos ser cada vez melhores, para também dar respostas educativas de cada vez mais qualidade. Nós queremos que as nossas práticas sejam de mais qualidade. (avaliação)

(educadora P1)

História 6

Eu gostei muito desta cumplicidade entre nós, houve uma cumplicidade. (resumo e avaliação)

Essa sua parte de observar e visualizar (complicação da ação)

também foi espetacular, eu gostei. (avaliação)

Deu-me uma certa segurança, deu-me uma certa preocupação porque tive que pensar muito bem nas coisas. Uma coisa é estarmos sozinhas com o grupo e estamos numa forma diferente; sabendo que está uma pessoa a observar temos uma preocupação acrescida. Temos uma certa preocupação a nível de discurso, a nível de resultados e do interesse das crianças. $E$ as próprias crianças nos respondem a isso, quando estou empenhada numa atividade e quando eu a desenvolvo como deve ser ou não. Portanto, a recetividade deles é completamente diferente. E também a nível de importância que eu dou às coisas. (resolução)

Portanto, até quando a S. [supervisora] vinha eles ficavam muito contentes. Foi um elemento muito bom na nossa sala. Nós estávamos todos no mesmo barco, no sentido de as coisas fazerem sentido, as crianças perceberem, de se tornar uma coisa interessante.

Portanto, não esteve aqui a dizer o que estava mal, houve uma cumplicidade. Tanto a S. como eu queríamos que as coisas resultassem bem a nível de experiências e a nível de práticas, e de eles próprios. $E$ isso também é bom para nós. (avaliação)

Sentiu-se uma cumplicidade, e foi bonito. (avaliação/coda)

(educadora P2) 
As histórias evidenciam algumas mudanças de atitude das educadoras perante a prática educativa. $O$ trabalho colaborativo com o supervisor provocou um maior interesse das educadoras pelo planeamento, ação e resultados das atividades propostas aos seus grupos de alunos (Vasconcelos, 2009). As educadoras P1 e P2, na "resolução", indicam esse percurso efetuado que as levou a algumas alterações nas práticas. A educadora P2 faz uma "avaliação" de criação de sentido do trabalho desenvolvido, para as crianças e também para ela. Nesta significação está implícita uma intenção pedagógica de adequação ao grupo, e que a educadora P1 avalia como "dar respostas educativas de cada vez mais qualidade". Este desenvolvimento profissional que as educadoras contam nas suas histórias permite a melhoria das práticas educativas promotoras de aprendizagens significativas para todos os intervenientes e, consequentemente, da qualidade educativa em jardim de infância (Bertram \& Pascal, 2009). Ambas as educadoras destacam uma maior segurança para investir nas suas práticas pedagógicas, e que este processo facilitou o empenho para planear, pesquisar e pensar as estratégias (P1) de modo a que as "coisas resultassem bem a nível de experiências e a nível de práticas, e de eles próprios" (P2).

Mas estas alterações nas práticas acontecem num processo reflexivo permanente. De facto, a reflexão apoiada num processo de supervisão ajudou na análise da ação educativa devidamente contextualizada, permitindo tomar decisões pedagógicas cada vez mais adequadas (Schön, 1983, cit. por Alarcão, 1996). Neste processo de melhoria de práticas, a construção de sentido da atividade pedagógica é reconhecida, pelas educadoras, em atitude de professor reflexivo crítico, mostrando-se disponível para o diálogo com outros (Brookfield, 1995), como mostram as histórias seguintes:

História 7

Todos estes momentos que aconteceram neste processo de supervisão, eu acho que eles são todos importantes, e todos eles contribuíram para a melhoria de prática. Mas, eu acho que (resumo)

o planear e o refletir foram importantes, são bases (complicação da ação)

apesar de eu achar que todas elas existem, porque tem que existir. 
(orientação)

Mas a reflexão e o planeamento e a negociação são importantes. $A$ reflexão então é que, de todas elas, é o momento-chave porque nos vai fazer o clic. (avaliação)

Aconteceu isto, porquê? Porque aconteceu? E depois permite reformular. (resolução)

Claro que também se prende com o tipo de atividades, há atividades que conseguimos reformular mais rapidamente do que outras, (Orientação)

mas o objetivo é mesmo esse: na próxima, nem que seja pouco, mas na próxima eu vou ser melhor com certeza. Eu vou ter outro tipo de ação muito mais enriquecedora, muito mais positiva, muito mais assertiva. (avaliação)

Eu acho que foi visível durante as atividades-(coda)

(educadora P1)

\section{História 8}

Eu acho que a supervisão é boa. E boa porque a supervisão ajuda na prática pedagógica, acho que a supervisão leva-nos. (resumo e avaliação)

Acho que a supervisão leva-nos a refletir um bocadinho mais sobre as coisas (complicação da ação).

E a supervisão tem que ser vista nesse sentido, de um processo colaborativo, de cooperação para que o resultado seja mais proveitoso para as crianças. Para nós o objetivo primordial é a criança, é que ela evidencie os seus conhecimentos, que ela goste de fazer a experiência, motivar e sensibilizar a criança para isso mesmo. (resolução)

Portanto, havendo uma supervisão, esta ajuda-nos a ter mais consciência das coisas em si, e de não levar as coisas de uma forma leve, e tão solta. Levou-me a melhorar a estrutura e o processo do desenrolar da experiência [atividade experimental em ciências]. (avaliação)

(educadora P2) 
As histórias 7 e 8 destacam, na "avaliação", a importância da reflexão em todo o processo de aprendizagem. É caracterizado como o momentochave pois, para P1, "vai fazer o clic" para que "na próxima [seja] melhor com certeza" e, na opinião de P2, "ajuda-nos a ter mais consciência das coisas em si". Todo o processo visiona uma prática mais intencional, mais consciente e informada, e permite que os "resultados sejam mais proveitosos para as crianças" (P2).

No que respeita à prática pedagógica, o processo de reflexão conjunta está contemplado também na "avaliação" das educadoras. Para P1 permitiu "ter outro tipo de ação muito mais enriquecedora, muito mais positiva, muito mais assertiva" e para P2, na mesma linha, levou-a "a melhorar a estrutura e o processo do desenrolar da experiência".

Esta perspetiva de desenvolvimento profissional teve como termo comparativo as práticas desenvolvidas antes do processo de supervisão. 0 processo de reflexão permitiu-lhes compreender e atribuir sentido à ação pedagógica, validando os seus saberes e competência profissional, de modo a aperfeiçoar as suas práticas.

\section{Síntese}

É num panorama de supervisão colaborativa e reflexiva que o desenvolvimento profissional acontece. Um supervisor apoiante comprometese com um processo de aperfeiçoamento de práticas (Glickman, 1980, cit. por Tracy, 2002) e conduz a aprendizagens de educadoras e crianças (Zeichner, 2008).

As histórias 3 e 4 identificam estilos de supervisão, o que só foi possível às educadoras por comparação de diferentes situações vividas. As histórias 5 e 6 reconhecem mudanças na atividade pedagógica, partindo de um melhor planeamento e, consequentemente, melhores resultados das atividades propostas. As educadoras revelam-se mais seguras e mais empenhadas nas atividades, o que Ihes permite uma atribuição de sentido ao trabalho desenvolvido. $O$ processo de reflexão é assinalado por ambas as educadoras, nas histórias 7 e 8 , como elemento-chave do desenvolvimento profissional, mobilizando práticas mais enriquecedoras para elas e para as crianças. Assumem a importância da supervisão na promoção de práticas de 
qualidade em educação de infância, com impacto em aprendizagens para elas próprias e para as crianças.

\section{Considerações finais}

O processo de supervisão colaborativa assume-se como um impulso no desenvolvimento profissional. É nas experiências diárias em contexto de jardim de infância que florescem as oportunidades de reflexão e atribuição de significado pessoal e profissional aos acontecimentos educativos experienciados. É neste panorama que a narrativa se mostra em ambos os momentos: relato das experiências educativas e interpretação das mesmas. É na narrativa que as educadoras, através de histórias, nos dão a conhecer o seu olhar sobre as suas práticas educativas, assumindo um carácter de reflexão pedagógica e formativa (Galvão, 2005).

Antes de se iniciar o processo de supervisão, as educadoras reconheciam a importância da colaboração no processo de supervisão, mais concretamente da parte do supervisor. No entanto, mostravam-se receosas por "quebrar a rotina" e até assumir as suas "fragilidades". A supervisão, por um lado, apresenta-se com importância para a melhoria da prática educativa, pois "trabalhamos connosco próprios", o que dificulta a reflexão e o desenvolvimento profissional; por outro lado, ela é um risco assumido de escrutínio da prática educativa desenvolvida em contexto.

Após o processo de supervisão, as educadoras foram alterando formas de atuar e pensar, nomeadamente assistiu-se a uma evolução do próprio conceito de supervisão. Estas relataram nas suas histórias dois estilos de supervisão: diretivo e colaborativo (Glickman, 1985). Encaram este último como beneficiador e impulsionador de uma melhoria da ação educativa, promovendo o desenvolvimento profissional, bem como aprendizagens nas crianças (Alarcão \& Canha, 2013).

Nas histórias contadas pelas educadoras, o processo de supervisão permitiu "que a intenção educativa fizesse sentido para o grupo e para mim enquanto educadora" (P1), e também que "as coisas resultassem de uma forma pedagogicamente mais correta" (P2). Os processos de planeamento e reflexão mostram-se fundamentais no seu desenvolvimento profissional e, consequentemente, na melhoria de práticas educativas promotoras de 
ganhos educacionais para as crianças, especialmente numa temática - as ciências - menos dominada pelas educadoras e, por isso, desencadeadora de insegurança ou mesmo medo de a iniciar na sala de aula. Assume-se um enriquecimento de práticas e de valorização de saberes profissionais de cada uma (Elbaz-Luwisch, 2005). A narrativa desvendou o processo de colaboração vivido e, ao mesmo tempo, permitiu, pelo facto de narrarem o modo como viveram esse processo, irem-se dando conta de como foi importante para o seu desenvolvimento profissional.

\section{Referências}

Alarcão, I. (1996). Ser professor reflexivo. In I. Alarcão (Org.), Formação reflexiva de professores. Estratégias de supervisão (pp. 171-189). Porto: Porto Editora.

Alarcão, I. (2002). Escola reflexiva e desenvolvimento institucional. Que novas funções supervisivas?. In J. Oliveira-Formosinho (Org.), A supervisão na formação de professores I. Da sala à escola (pp. 217- 238). Porto: Porto Editora.

Alarcão, I., \& Canha, B. (2013). Supervisão e colaboração: Uma relação para o desenvolvimento. Porto: Porto Editora.

Alarcão, I., \& Roldão, M. C. (2008). Supervisão: Um contexto de desenvolvimento profissional dos professores. Mangualde: Edições Pedago.

Bertram, T., \& Pascal, C. (2009). Desenvolvendo a qualidade em parcerias. Lisboa: DGIDC.

Brookfield, S. (1995). Becoming a critically reflective teacher. San Francisco: JosseyBass Publishers.

Bruner, J. (1972). The nature and uses of immaturity. American Psychologist, 27(8), 687708.

Bruner, J. (1997). Atos de significação. Porto Alegre: Artmed Editora.

Carter, K. (1993). The place of story in the study of teaching and teacher education. Educational Researcher, 22(1), 5-12.

Clandinin, D., \& Connelly, F. (2000). Narrative inquiry: Experience and story in qualitative research. San Francisco: Jossey-Bass Publishers.

Cohen, L., Manion, L., \& Morrison, K. (2000). Research methods in education. New York: Routledge.

Connelly, M., \& Clandinin, J. (1990). Stories of experience and narrative inquiry. Educational Researcher, 19(5), 2-14.

Creswell, J. (2003). Research design: Qualitative, quantitative and mixed methods approaches. Londres: Sage Publications.

Elbaz-Luwisch, F. (2005). Teacher's voices. Storytelling \& possibility. USA: Information Age Publishing Greenwich. 
Elbaz-Luwisch, F. (2007). Studying teachers lives and experience. In D. Clandinin, Handbook of narrative inquiry. Mapping a methodology (pp. 357-382). California: Sage Publications.

Fullan, M. (1982). The meaning of educative change. Toronto: Oise Press.

Galvão, C. (2005). Narrativas em educação. Ciência \& Educação, 11(2), 327-345.

Garmston, R., Lipton, L., \& Kaiser, K. (2002). A psicologia da supervisão. In J. OliveiraFormosinho (Org.), A supervisão na formação de professores II. Da organização à pessoa (pp. 17 132). Porto: Porto Editora.

Glickman, C. (1985). Supervision of instruction - A development approach. Massachusetts: Allyn and Bacon.

Josso, M. C. (2004). Experiências de vida e formação. São Paulo: Editora Cortez.

Labov, W. (1972). The transformation of experience in narrative sintax. In W. Labov (Ed.), Language in the inner city (pp. 352-396). Philadelphia: University of Pennsylvania.

Labov, W. (1982). Speech actions and reactions in personal narrative. In D. Tannen (Ed.), Analyzing discourse: Text and talk (pp. 12-44). Washington: Georgetown University Press.

Moss, P., Dahlberg, G., \& Pence, A. (2000). Getting beyond the problem with quality. European Early Childhood Education Research Journal, 8(2), 103-115.

Nóvoa, A. (1992). Formação de professores e profissão docente. In A. Nóvoa (Org.), Os professores e a sua profissão. (pp.15-33). Lisboa: Publicações Dom Quixote.

Oliveira, L. (1992). O clima e o diálogo supervisivo na supervisão de professores. Cadernos CIDInE, 1, 13-22.

Perrenoud, P. (1993). Práticas pedagógicas, profissão docente e formação: Perspectivas sociológicas. Lisboa: Dom Quixote.

Reiman, A. J., \& Thies-Sprinthall, L. (1998). Mentoring and supervision for teacher development. New York: Addison-Wesley Longman.

Reis, P. (2008). As narrativas na formação de professores e na investigação em educação. Nuances: Estudos sobre Educação, 15(16), 17-34.

Riessman, C. (1993). Narrative analysis. Qualitative research methods. Newbury Park, CA: Sage.

Roldão, M. C. (2004). Transversalidade e especificidade no currículo - Como se constrói o conhecimento? Infância e Educação - Investigação e Práticas, Revista do GEDEI (Grupo de Estudos para o Desenvolvimento da Educação de Infância), 6, 61-72.

Sá-Chaves, I. (2000). Formação, conhecimento e supervisão. Contributos nas áreas de formação de professores e de outros profissionais. Aveiro: Universidade de Aveiro

Sá-Chaves, I. (2002). A construção do conhecimento pela análise reflexiva da praxis. Lisboa: Fundação Calouste Gulbenkian e Fundação para a Ciência e Tecnologia.

Sá-Chaves, I. (2011). Formação, conhecimento e supervisão: Contributos nas áreas de formação de professores e de outros profissionais. Aveiro: Universidade de Aveiro. 
Stephens, J. (1992). Language and ideology in children's literature. New York: Longman Publishing.

Tracy, S. (2002). Modelos e abordagens. In J. Oliveira-Formosinho (Org.), A supervisão na formação de professores I. Da sala à escola (pp. 19- 92). Porto: Porto Editora.

UNESCO (1998). Professores e ensino num mundo em mudança. Relatório mundial de educação. Lisboa: Edições ASA.

UNESCO (2010). Educación para todos: El informe de seguimiento 2010: Llegar a los marginados. Oxford: UNESCO.

Vasconcelos, T. (2009). Prática pedagógica sustentada. Cruzamento de saberes e de competências. Lisboa: Edições Colibri.

Vieira, F. (1993). Supervisão: Uma prática reflexiva de formação de professores. Porto: Edições ASA.

Woodhead, M. (1996). In search of rainbow. Pathways to quality in large-scale programmes for young disadvantaged children. The Hague: Brenard Van Leer Foundation.

Zeichner, K. (1993). A formação reflexiva de professores: Ideias e práticas. Lisboa: Educa.

Zeichner, K. (2008). Uma análise critica sobre a "reflexão" como conceito estruturante na formação docente. Educação \& Sociedade, 29(103), 535-554.

\section{Legislação consultada}

Parecer $n^{\circ} 3 / 2009$, de 26 de junho. Diário da República, 2. ${ }^{a}$ série, N. ${ }^{\circ} 122$. 


\section{SUPERVISION PROCESS IN A KINDERGARTEN. A NARRATIVE LOOK TOWARDS PROFESSIONAL DEVELOPMENT}

\section{Abstract}

This article is based on a supervision process that aimed to listen to two childhood educators that told their experiences, in order to share their educational practices. This collaborative supervision process was evidenced in the stories of the educators as promoters of professional development and improvement of the educational practices. The reflection is the central element for this development, allowing the attribution of meaning to the pedagogical action. The study has a qualitative and interpretative nature. The narrative was the method of listening and reflection, using Labov's model (1972/1982) for the analysis of the narratives. This study suggests that the integrated reflection process in the supervision allowed for the improvement of the educational practices and, consequently, professional development. While telling their stories, the educators remembered, analyzed and incorporated the reflection of their educational experiences in their practices.

Keywords

Supervision; Childhood education; Professional development; Narratives

PROCESSUS DE SUPERVISION EN MATERNELLE. UNE PERSPECTIVE NARRATIVE QUI A POUR BUT LE DÉVELOPPEMENT PROFESSIONNEL

\section{Résumé}

Cet article a comme base un processus de supervision qui visait l'écoute de deux assistantes maternelles qui nous ont racontés leurs expériences, de façon à nous faire connaître leurs pratiques éducatives. Ce processus de supervision collaborative et de réflexion a été mis en évidence dans les récits des assistantes maternelles, quand elles indiquent que celui-ci promeut le développement professionnel et l'amélioration des pratiques éducatives, 
faisant de la réflexion l'élément central pour ce développement, permettant l'attribution d'un sens à l'action pédagogique. Cette étude est de nature qualitative et interprétative et a comme fil conducteur l'écoute et la réflexion, utilisant pour l'analyse des narratives le modèle évaluateur de Labov (1972, 1982).Cette étude suggère que le processus de réflexion, intégré à la supervision, a permis une amélioration des pratiques éducatives et, par conséquent, le développement professionnel. En racontant leurs histoires, les assistantes maternelles se rappellent, analysent et incorporent la réflexion sur leurs expériences éducatives dans leur pratique.

Mots-clé

Supervision; Éducation de l'enfance; Développement professionnel; Narratives

Recebido em junho/2014 Aceite para publicação em agosto/2014

i Escola Superior de Educação de Torres Novas, Portugal.

ii Instituto de Educação, Universidade de Lisboa, Portugal.

Toda a correspondência relativa a este artigo deve ser enviada para: Susana Diogo Meirinho. Rua do Pinhal, $n^{\circ}$ 5, Casal Domingos João. 2435-523 Rio de Couros - Ourém. E-mail: sdmeirinho@hotmail.com 